\title{
B-SHOT a New Technique in Genital Area Rejuvenation; Co-Injection of Stromal Vascular Fraction and Adipose-Derived Mesenchymal Stem Cell
}

\section{Bülent Cihantimur*, Özgür Ağlamiş and Yavuz Özsular}

Department of Plastic Surgery, Estetik International Quasar Clinic, Turkey

*Corresponding Author: Bülent Cihantimur, Department of Plastic Surgery, Estetik International Quasar Clinic, Turkey.
Received: January 20, 2021

Published: May 29, 2021

(C) All rights are reserved by Bülent

Cihantimur., et al.

\begin{abstract}
Purpose: We named the co-injection of stromal vascular fraction (SVF) and adipose-derived mesenchymal stem cell, which are cells with the highest regenerative capacity of the body derived from adipose tissue, as B-SHOT rejuvenation and investigated whether this new technique is effective in genital area rejuvenation.

Material and Method: 40 female participants participated in the present study. $40 \mathrm{cc}$ lipoaspiration material was reached from the abdominal region. By using fat micronizing device, lipoaspirate was subjected to non-enzymatic mechanical filtration up to 400 microns and then centrifuged. The obtained Stromal Vascular Fraction (FAT JUICE) and adipose derived mesenchymal stem cells were injected with our B-SHOT technique to the clitoris, around the openings of skene glands, vaginal mucosa, and G spot area. All participants were evaluated with VHI and FSFI before and after the application in the $3^{\text {rd }}, 6^{\text {th }}, 9^{\text {th }}$ and $12^{\text {th }}$ months.

Results: Elasticity, vaginal $\mathrm{pH}$ and humidity scores from VHI parameters significantly increased in the $3^{\text {rd }}$ and $6^{\text {th }}$ months after treatment $(p<0.001)$. In addition, significant increase in the score of the new parameter continued in the $9^{\text {th }}$ month, as well ( $\left.p<0.05\right)$. Scores of orgasm, satisfaction and pain among FSFI parameters significantly increased in the $3^{\text {rd }}$ and $6^{\text {th }}$ months after treatment.

Conclusion: Our B-SHOT technique may be a new practical rejuvenation protocol for genital rejuvenation, which is a low cost, safe, effective technique, prepared within a short time without the need for additional staff or laboratory and benefits from the regenerative effect of adipose derived mesenchymal stem cells in SVF.
\end{abstract}

Keywords: B-SHOT; Genital Rejuvenation; Adipose Derived Mesenchymal Stem Cell; Stromal Vascular Fraction

\section{Abbreviations}

HA: Hyaluronic Acid; PRP: Platelet Rich Plasma; ADMSC: Adipose Derived Mesenchymal Stem Cells; HLADR: Human Leukocyte Antigen-DR isotype; SVF: Stromal Vascular Fraction; US FDA: American Food and Drug Administration; RCF: Relative Centrifugal Force; VHI: Vaginal Health Index; FSFI: Female Sexual Function Index; SD: Standard Deviation

\section{Introduction}

New studies on the field of genital rejuvenation having a wide range of treatments can be prepared more permanently and in a shorter time and it is about putting more practical, more economical and safer applications into our practice. In this field, stem cell treatments are promising in genital rejuvenation applications. Clinical studies show that not only tissue repairing effects but also anti-aging effects of Adipose Derived Mesenchymal Stem Cells (AD- 
MSC) treatments will increase its popularity [1]. ADMSCs have a unique regenerative potential. They exhibit angiogenic, immunosuppressive, anti-inflammatory, and antioxidative effects with their secreted cytokines and they can also differentiate into adipocytes, osteoblasts, myocytes, chondrocytes, endothelial cells and cardiomyocytes [2]. These regenerative potentials of stem cells attract the attention of clinicians interested in genital rejuvenation.

Although ADMSCs were obtained only from bone marrow in the past, as a result of the studies, Zuk., et al. determined that adipose tissue also contained stem cells and this study has been an important milestone in stem cell studies [3]. The studies have shown that adipose tissue contains ADMSCs hundreds of times greater than bone marrow [4]. Again, in another study comparing bone marrow and adipose tissue in terms of the number of ADMSC they contain, adipose tissue was found to contain at least 50 times more stem cells [5]. When compared to bone marrow, known to be the most important source of stem cells until now, interest in adipose tissue and adipose derived mesenchymal stem cells has increased rapidly in recent years due to its easier access and potential to obtain more cells [6]. First clinical studies have shown that autologous and allogenic ADMSCs can be transplanted without immune rejection [7]. The reason why there is no tissue rejection is that Human Leukocyte Antigen - DR isotype (HLADR) expression is not seen in ADMSCs [8]. This makes stem cell injection safe compared to other foreign material injections.

The content of adipose tissue is divided into two main components including mature adipocytes and Stromal Vascular Fraction (SVF). SVF includes smooth muscle cell, endothelial cell, erythrocyte, leukocyte, pre-adipocyte and ADMSC [9]. In order to obtain SVF from adipose tissue, enzymatic degradation process using collagenase is required. The presence of collagenase in the injectable product of adipose tissue is more advanced than the "minimal manipulation" defined by the American Food and Drug Administration (U.S FDA) as a process that does not alter the original biological properties of cells [10]. Because of this disadvantage, non-enzymatic SVF production applications have increased due to the effect of mechanical destruction without enzymatic degradation.

The most important study in this issue is the one conducted by Tonnard., et al. in 2013 in which the final product, obtained as a result of emulsification and filtration of lipoaspirate, was called as Nanofat. Nanofat has entered into the medical literature with this study [11]. In this study, an alternative genital rejuvenation protocol, we called B-SHOT ${ }^{\circledR}$, that can be applied with a thin needle tip up to $30 \mathrm{G}$ below 400 micron by using a special mechanical filter, a special preparation and application technique, and its effectiveness were investigated by obtaining total cell and nucleated cell with a denser concentration than Nanofat in milliliters in order to obtain ADMSC with very high regenerative potential from lipoaspirate.

\section{Materials and Methods}

Forty women with regular menstrual cycles between 2018 and 2019 participated in the present study. The reasons for the patients to apply to the clinic were having sexual arousal problems, not having sufficient orgasms or having no orgasm, low sexual satisfaction, not getting enough wetness during sexual intercourse and feeling dryness and pain. The participants who used any oral contraceptive drugs, vaginal or oral estrogen, vaginal moisturizer, vaginal lubricant gel or foam, had vaginal PRP, vaginal HA (gel/injection) treatment within last 3 months were excluded from the study. The present study was conducted according to the ethical principles determined in the Declaration of Helsinki. All the participants signed a detailed consent form.

The liposuction part of B SHOT procedure was performed under local infiltration anesthesia. For infiltration anesthesia, $1 \mathrm{ml}$ Bupivacaine hydrochloride (0.5\%), $1 \mathrm{ml}$ Lidocaine hydrochloride (20 mg/ml), and 0.1 Adrenaline $(1 \mathrm{mg} / \mathrm{ml})$ were mixed in $100 \mathrm{cc}$ Lactated Ringer solution and applied to the abdominal area. After waiting for 5 minutes, $40 \mathrm{cc}$ lipoaspirate was reached from each participant by conducting lipoaspiration through aspiration cannulas with $3 \mathrm{~mm}$ diameter, multiple holes and $2 \mathrm{~mm}$ hole width from the abdominal area. After decantation of ten minutes, $20 \mathrm{cc}$ infranatant fluid was removed.

After removing infranatant fluid, fat micronizing device was used to micronize, homogenize and filter the remaining adipose tissue.

By separating $20 \mathrm{cc}$ lipid, they were taken into a special $20 \mathrm{cc}$ injector fat micronizing device filtering and micronizing kit was installed on the injector tip and by installing the special $20 \mathrm{cc}$ injector to the other open end of the kit, fat micronizing device was ensured to remain between the two injectors. The process was initiated with 2400 micron fat micronizing device $20 \mathrm{cc}$ adipose was filtered, micronized and homogenized by passing through the in- 
jector to injector 20 times in a way to pass through the kit each time between the two injectors. fat micronizing device ensures to reach Stromal Vascular Fraction without damaging the extracellular matrix in adipose tissue with its blade and micro porous structure in different sizes and shapes in its patented design. The same process was carried out 20 times with the transition from injector to injector with 1200 micron, 600 micron and 400 micron fat micronizing devices, respectively.

During the procedure, $2 \mathrm{cc}$ adipose tissue remained in the kits during the fat micronizing device transitions of different sizes and was lost mechanically as a residual adipose tissue. The remaining $18 \mathrm{cc}$ adipose tissue was divided into two, $9 \mathrm{cc}$ each, and taken into $10 \mathrm{cc}$ locked injectors and subjected to centrifugation for 4 minutes with 1800 RCF (Relative Centrifugal Force).

After centrifugation, $3 \mathrm{cc}$ reddish colored liquid at the top of each injector and $6 \mathrm{cc}$ residual adipose tissue at the bottom of each injection were obtained. This reddish colored liquid is equivalent to Stromal Vascular Fraction obtained through enzymatic way. We call this rich, reddish liquid with high regenerative capacity obtained from adipose derived mesenchymal stem cells, growth factors and interleukins which were obtained after the process, as FAT JUICE (Figure 1).

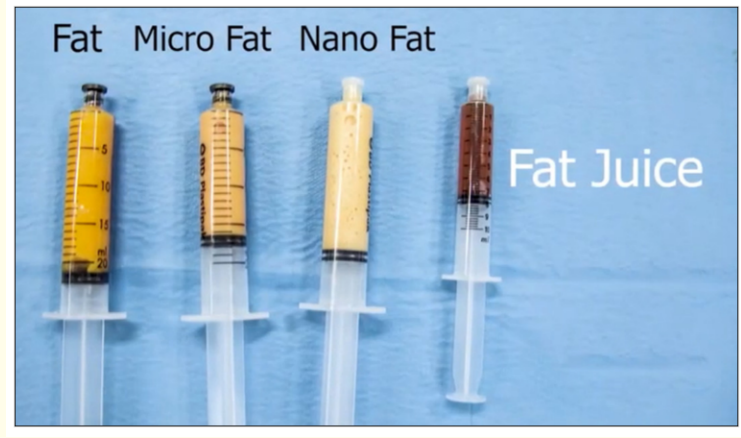

Figure 1: FATJUICE preparation.

Before applying to genital area, FAT JUICE was counted using LUNA-STEM $^{\text {TM }}$ AUTOMATED FLUORESCENCE CELL COUNTER FOR STEM CELLS and SVF device and total cell count, nuclear cell count and viability rate were calculated.
For the counting, 1.8 microliter FAT JUICE was mixed with 0.2 microliter LOGOS Biosystems Acridine Orange \& Propidium Iodide staining and 1 microliter sample was placed into LUNA-STEM ${ }^{T M}$ device. While Acridine Orange penetrates into live nuclear cells and stains them green, Propidium iodide penetrates into dead nuclear cells and stains them red. In the counting performed with Dual Fluorescence technique, it was found that the mean total cell count was $2.39 \times 10^{6} \mathrm{cell} / \mathrm{cc}$, the mean number of nuclear cells was $1.93 \times 10^{6}$, and viability was $96 \%$ (n:40).

\section{B-Shot technique}

The vulva and vaginal canal were cleaned with Polyvinylpyrrolidone-iodine complex (Batticon) containing 10\% free iodine. 6 cc FAT JUICE in total were applied to the genital area with needle tips of 27 G $40 \mathrm{~mm}$ and $30 \mathrm{G} 1 / 20.3 \times 13 \mathrm{~m}$. During the procedure, the patient was under sedation anesthesia. Bolus injection of 1 cc FAT JUICE was carried out at a depth of $1.5 \mathrm{~mm}$ in the lower and upper parts of glans clitoridis in $0.5 \mathrm{cc} \times 2$ with $30 \mathrm{G}$ needle at a 90-degree angle. 2 cc FAT JUICE was injected into the area with $27 \mathrm{G}$ needle tip into the upper wall of the vagina, which also have the G spot with the angles of 15 30 degrees through point by point technique. $0.5 \mathrm{cc}$ FAT JUICE was injected around the opening of both skene glands with $30 \mathrm{G} 1 / 2$ needle tip at the angles of 15-30 degrees. The remaining 2 cc FAT JUICE was injected superficially with $27 \mathrm{G}$ needle tip using point by point technique at the angels of 15 - 30 degrees in a way to sweep the side and back wall of entire vagina. During the process, a 1 - $1.5 \mathrm{~mm}$ depth line was used.

No antibiotic or vaginal bougie was recommended to the participants after the procedure. After the procedure, no complications were observed except for mild redness, itching, spot bleeding foci in the form of leakage in the short term. Sexual intercourse was prohibited to all participants during the $1^{\text {st }}$ week after the procedure.

Evaluation of the results with vaginal health index (VHI) and female sexual function index (FSFI)

All participants were evaluated with Vaginal Health Index (VHI) and Female Sexual Function Index (FSFI) in the $3^{\text {rd }}, 6^{\text {th }}, 9^{\text {th }}$ and $12^{\text {th }}$ months after the application.

Vaginal Health Index consists of 5 parameters. These are vaginal elasticity, type and consistency of vaginal fluid secretion, vaginal $\mathrm{pH}$, evaluation of epithelial mucosa and vaginal moisture (Table 1). 


\begin{tabular}{|l|c|c|c|c|c|}
\hline Score & $\begin{array}{c}\text { Overall } \\
\text { elasticity* }\end{array}$ & $\begin{array}{c}\text { Fluid secretion type and } \\
\text { consistency }\end{array}$ & pH & Epithelial mucosa & Moisture \\
\hline 1 & None & None & 6.1 & Petechiae noted before & $\begin{array}{c}\text { None, mucosa } \\
\text { inflamed }\end{array}$ \\
\hline 2 & Poor & Scant, thin yellow & $5.6-6.0$ & Bleeds with light contact & $\begin{array}{c}\text { None, mucosa } \\
\text { inflamed }\end{array}$ \\
\hline 3 & Fair & Superficial, thin white & $5.1-5.5$ & Bleeds with scraping & Minimal \\
\hline 4 & Good & Moderate, thin white & $4.7-5.0$ & Not friable, thin mucosa & Moderate \\
\hline 5 & Excellent & Normal (white flocculent) & $\leq 4.7$ & Not friable, normal mucosa & Normal \\
\hline
\end{tabular}

Table 1: Vaginal health index (VHI).

Each parameter is rated between 1 and 5 points. The minimum score of Vaginal Health Index is 5 and its maximum score is 25. In a study showing that VHI is an important reference value for vaginal health, index score higher than fifteen points was accepted as normal [12]. Vaginal examinations of all participants were performed by a specialist gynecologist in our clinic. Vaginal pH was measured with disposable TST CHECK pH Test Strip.
Female Sexual Function Index (FSFI) is a questionnaire, filled out by the participants themselves, consisting of 19 questions and 6 domains [desire, arousal, lubrication, orgasm, satisfaction, pain] (Table 2). The minimum score is 2 and the maximum score is 36 . In a study, FSFI was specified as the gold standard for the assessment of therapeutically induced change in female sexual function [13]. Scores less than 26 points are accepted as an indicator of female sexual dysfunction [14].

\begin{tabular}{|l|c|c|c|c|c|c|}
\hline \multicolumn{1}{|c|}{ Domain } & Questions & $\begin{array}{c}\text { Score } \\
\text { Range }\end{array}$ & Factor & $\begin{array}{c}\text { Minimum } \\
\text { Score }\end{array}$ & $\begin{array}{c}\text { Maximum } \\
\text { Score }\end{array}$ \\
\hline Desire & 1,2 & $1-5$ & 0.6 & 1.2 & 6.0 & 6.0 \\
\hline Arousal & $3,4,5,6$ & $0-5$ & 0.3 & 0 & 6.0 & 6.0 \\
\hline Lubrication & $7,8,9,10$ & $0-5$ & 0.3 & 0 & 0 & 6.0 \\
\hline Orgasm & $11,12,13$ & $0-5$ & 0.4 & 0.4 & 6.0 & \\
\hline Satisfaction & $14,15,16$ & 0 (or 1$)-5$ & 0.4 & 0 & \\
\hline Pain & $17,18,19$ & $0-5$ & 0.4 & 2.0 & \\
\hline Full Scale Score Range & & & & & \\
\hline
\end{tabular}

Table 2: Female sexual function index (FSFI).

\section{Statistical analysis}

Data coding and statistical analysis were performed in computer environment through SPSS 22 software (IBM SPSS Statistics, IBM Corporation, Chicago, IL). Friedman test was used to analyze the discrete data. Parameters were expressed as mean \pm standard deviation (SD). All $p$ values of $<0.05$ were considered as statistically significant.

\section{Results}

In order to compare VHI and FSFI scores before the treatment and $3^{\text {rd }}, 6^{\text {th }}, 9^{\text {th }}$ and $12^{\text {th }}$ months after the treatment, 40 patients were evaluated prospectively.

While the mean age of the patients was $39.3 \pm 4.3$, their mean BMI was $26.9 \pm 4.5$. Elasticity, vaginal $\mathrm{pH}$ and moisture scores from VHI parameters increased in the $3^{\text {rd }}$ and $6^{\text {th }}$ months after the 
treatment. This difference was statistically significant and treatment significantly improved these parameters $(\mathrm{p}<0.001)$. In addition, significant score increase in moisture parameter continued also in the $9^{\text {th }}$ month $(\mathrm{p}<0.05)$. While VHI mean score obtained by summing the scores of VHI parameters was $14.1 \pm 1.9$ in the pre-treatment period, this value increased to $17.4 \pm 1.6$ and 21.2 \pm 1.4 in the post-treatment $3^{\text {rd }}$ and $6^{\text {th }}$ months, respectively. In the $9^{\text {th }}$ and $12^{\text {th }}$ months after the treatment, these values became 21.3 \pm 1.2 and $21.2 \pm 1.6$, respectively. The difference between the VHI mean scores in pre-treatment period and in the post-treatment $3^{\text {rd }}$ and $6^{\text {th }}$ months was statistically significant $(\mathrm{p}<0.001)$. Although VHI mean score increased in the $9^{\text {th }}$ month and decreased in the $12^{\text {th }}$ month, no statistically significant difference was observed between them $(p>0.05)$ (Table 3).

\begin{tabular}{|l|c|c|c|c|c|}
\hline VHI parameters & $\begin{array}{c}\text { Before treatment } \\
\text { (mean } \mathbf{4} \text { SD) }\end{array}$ & $\begin{array}{c}\mathbf{3}^{\text {rd }} \text { month } \\
\text { (mean } \pm \text { SD) }\end{array}$ & $\begin{array}{c}6^{\text {th }} \text { month } \\
\text { (mean } \pm \text { SD) }\end{array}$ & $\begin{array}{c}\text { 9 }^{\text {th }} \text { month } \\
\text { (mean } \pm \text { SD) }\end{array}$ & $\begin{array}{c}\mathbf{1 2}^{\text {th }} \text { month } \\
\text { (mean } \pm \text { SD) }\end{array}$ \\
\hline Elasticity & $2.8 \pm 0.9$ & $3.9 \pm 0.7^{\mathrm{x}}$ & $5 \pm 0.4^{\mathrm{x}}$ & $4.9 \pm 0.5^{\mathrm{z}}$ & $4.9 \pm 0.6^{\mathrm{z}}$ \\
\hline Liquid volume & $2.7 \pm 0.7$ & $2.9 \pm 0.7^{\mathrm{y}}$ & $3.5 \pm 0.6^{\mathrm{z}}$ & $3.3 \pm 0.5^{\mathrm{z}}$ & $3.3 \pm 0.7^{\mathrm{z}}$ \\
\hline pH & $2.7 \pm 0.8$ & $3.9 \pm 0.6^{\mathrm{x}}$ & $4.7 \pm 0.8^{\mathrm{x}}$ & $4.8 \pm 0.6^{\mathrm{z}}$ & $4.7 \pm 0.6^{\mathrm{z}}$ \\
\hline Epithelial mucosa & $2.9 \pm 0.9$ & $3 \pm 0.8^{\mathrm{z}}$ & $3.4 \pm 0.8^{\mathrm{z}}$ & $3.5 \pm 0.7^{\mathrm{z}}$ & $3.4 \pm 0.8^{\mathrm{z}}$ \\
\hline Moisture & $2.9 \pm 0.8$ & $3.9 \pm 0.9^{\mathrm{x}}$ & $4.7 \pm 0.8^{\mathrm{x}}$ & $4.9 \pm 0.6^{\mathrm{y}}$ & $4.9 \pm 0.7^{\mathrm{z}}$ \\
\hline Total score & $14.1 \pm 1.9$ & $17.4 \pm 1.6^{\mathrm{x}}$ & $21.2 \pm 1.4^{\mathrm{x}}$ & $21.3 \pm 1.2^{\mathrm{z}}$ & $21.2 \pm 1.6^{\mathrm{z}}$ \\
\hline
\end{tabular}

Table 3: Comparison of pre-treatment and post-treatment values of the patients with their vaginal health index mean scores. x: $<<0.001$, : $:$ p $<0.05,{ }^{z}: p>0.05, V H I:$ Vaginal Health Index, SD: Standard Deviation.

Orgasm, satisfaction and pain scores from FSFI parameters increased in the $3^{\text {rd }}$ and $6^{\text {th }}$ months. This difference was statistically significant and treatment significantly improved these parameters ( $\mathrm{p}<0.001$ ). While VHI mean score obtained by summing the scores of FSFI parameters was $22.8 \pm 1.5$ before the treatment, this value increased to $28.1 \pm 1.6$ and $31.5 \pm 1.5$ in the $3^{\text {rd }}$ and $6^{\text {th }}$ months, respectively. These values became $31 \pm 1.6$ and $30.3 \pm 1.7$ in the $9^{\text {th }}$ and $12^{\text {th }}$ months after treatment. The difference between the FSFI scores in pre-treatment period and $3^{\text {rd }}$ and $6^{\text {th }}$ months after treatment was statistically significant ( $p<0.001)$. The FSFI mean score decreased statistically significantly between the $9^{\text {th }}$ and $12^{\text {th }}$ months ( $\mathrm{p}<0.001)$. Nevertheless, it preserved its success compared to the pre-treatment period (Table 4).

\begin{tabular}{|l|c|c|c|c|c|}
\hline FSFI parameters & $\begin{array}{c}\text { Before treatment } \\
\text { (Mean } \pm \text { SD) }\end{array}$ & $\begin{array}{c}\mathbf{3}^{\text {rd }} \text { month } \\
\text { (mean } \pm \text { SD) }\end{array}$ & $\begin{array}{c}\mathbf{6}^{\text {th }} \text { month } \\
\text { (mean } \pm \text { SD) }\end{array}$ & $\begin{array}{c}9^{\text {th }} \text { month } \\
\text { (mean } \pm \text { SD) }\end{array}$ & $\begin{array}{c}\mathbf{1 2}^{\text {th }} \text { month } \\
\text { (mean } \pm \text { SD) }\end{array}$ \\
\hline Sexual desire & $3.2 \pm 0.5$ & $3.2 \pm 0.4^{z}$ & $3.1 \pm 0.6^{z}$ & $3.2 \pm 0.6^{z}$ & $3.1 \pm 0.5^{z}$ \\
\hline Arousal & $3.1 \pm 0.6$ & $3 \pm 0.6^{z}$ & $3.1 \pm 0.4^{z}$ & $3 \pm 0.5^{z}$ & $3 \pm 0.6^{z}$ \\
\hline Lubrication & $4.1 \pm 0.5$ & $4.2 \pm 0.6^{z}$ & $4.1 \pm 0.4^{z}$ & $4 \pm 0.7^{z}$ & $4.2 \pm 0.5^{z}$ \\
\hline Orgasm & $4.1 \pm 0.6$ & $5.6 \pm 0.7^{x}$ & $7.9 \pm 0.8^{x}$ & $7.5 \pm 0.5^{y}$ & $7.2 \pm 0.6^{y}$ \\
\hline Satisfaction & $3.6 \pm 0.6$ & $4.9 \pm 0.7^{x}$ & $6.5 \pm 0.7^{x}$ & $6.6 \pm 0.7^{z}$ & $6.4 \pm 0.4^{z}$ \\
\hline Pain & $4.6 \pm 0.6$ & $6.1 \pm 0.7^{x}$ & $6.8 \pm 0.5^{x}$ & $6.7 \pm 0.6^{z}$ & $6.4 \pm 0.7^{y}$ \\
\hline Total score & $22.8 \pm 1.5$ & $28.1 \pm 1.6^{\mathrm{z}}$ & $31.5 \pm 1.5^{\mathrm{x}}$ & $31 \pm 1.6^{\mathrm{z}}$ & $30.3 \pm 1.7^{\mathrm{z}}$ \\
\hline
\end{tabular}

Table 4: Comparison of pre-treatment and post-treatment values of the patients with their female sexual function index mean scores. $\mathrm{x}: \mathrm{p}<0.001,{ }^{\mathrm{y}}: \mathrm{p}<0.05,{ }^{\mathrm{z}}: \mathrm{p}>0.05$, SD: Standard Deviation, FSFI: Female Sexual Function Index. 


\section{Discussion}

Since enzymatic degradation protocols using collagenase affect cells in advance level than "minimal manipulation" defined by the American Food and Drug Administration as the process that does not change the original biological properties of the cells, it has been the disadvantage of these enzymatic systems. In addition, since enzymatic degradation protocols require private labs and personnel, they are the methods that are difficult to use in practice, high cost and time consuming. Due to these disadvantages, the mechanical degradation protocols have started to gain popularity. As expected, the cellular efficiency obtained from the mechanical procedures in obtaining SVF is lower compared to enzymatic methods. This is because releasing adipose tissued tightly bound with collagen by mechanical effect alone would not be as effective as using collagenase $[15,16]$. In another study, it was stated that SVF obtained with mechanical techniques had low differentiation capacity but showed high immunomodulatory effect due to its intense cytokine and growth factor contents [17]. Unlike these studies, in their study Condé-Green A., et al. revealed that SVF obtained with mechanical method had the same number of cells, viability and differentiation capacity as the one obtained with enzymatic method [18]. In the previous studies, it was determined SVF cell yield per 1 gr adipose tissue was $2 \times 10^{4}-2 \times 10^{6}$ nuclear cells [19]. In the study by L Aust., et al. $5 \times 10^{4}-2 \times 10^{5}$ stem cells were isolated for 1 gr adipose tissue. In their nonenzymatic SF production study, Raposio., et al. obtained $1 \times 10^{7}$ cells for $80 \mathrm{ml}$ lipoaspirate. It was determined that $5 \%$ of this amount was ADMSC. In the present study, it was found that the mean total cell count of SVF we obtained mechanically through non-enzymatic way was $2.39 \times 10^{6}$ cell/cc, mean nuclear cell count was $1.93 \times 10^{6}$, and viability was $96 \%$ in the counting process conducted with Dual Fluorescence technique (n:40). 10 - 15\% of the count of nuclear cells is ADMSC. This high cell yield and viability rate in the present study supports the study of Condé-Green A., et al. showing that mechanical methods are as effective as enzymatic methods [18]. In addition, SVF (FAT JUICE) rich in ADMSC having a high regenerative effect provides an advantage as a practical and low cost system that has 15 minutes of preparation and allows to reach quickly to the final product in the operation room without the need for additional staff and laboratory.

With the paracrine effect of the cytokines they secrete, ADMSCs remodel the extracellular matrix, induce angiogenesis, provide fibroblast mitosis, and inhibit the aging process with the antioxidant ef- fect. For example, CD44 is known as the hyaluronic acid receptor and decreases with age. ADMSC cytokines act as a hyaluronic acid receptor by contributing to CD44 secretion and show an antiaging effect [20]. It was shown in the study by Atalay., et al. that SVF accelerated cell proliferation, increased vascularization, reduced inflammation, and accelerated wound healing process by increasing fibroblast activity [21]. In the study conducted by Rigotti., et al. on skin rejuvenation, it was stated that positive outcomes were obtained in a short time like 3 months after SVF or ADMSC application [22]. In another study conducted on skin, it was shown that skin flushing increased in the application area after SVF treatment [23]. Additionally, it was determined that ADMSCs showed anti-inflammatory response in the area they were applied and contributed to the regenerative effect [24]. In the present study, it was also found that these regenerative effects of ADMSCs for genital rejuvenation led to improvement in VHI and FSFI scores.

Cheng., et al. stated that elasticity and flushing increased in the operation area where SVF was applied after skin grafting [25]. In the present study, elasticity, vaginal $\mathrm{pH}$ and moisture scores from VHI parameters increased in the $3^{\text {rd }}$ and $6^{\text {th }}$ months after treatment. This difference was statistically significant and the treatment improved these parameters significantly $(\mathrm{p}<0.001)$. In addition, the significant score increase in moisture parameter continued in the $9^{\text {th }}$ month, as well. The positive improvement in VHI parameters also positively affected FSFI scores. The fact that vaginal $\mathrm{pH}$ and moisture parameters improved and vaginal elasticity improved significantly depending on the increased vaginal flushing after our treatment showed the positive correlation between the present study and Cheng., et al. study.

In the present study, the final product, we call as FAT JUICE was obtained by centrifuging Nanofat, which was mechanically reduced to less than 400 microns, again; thus, by removing lipid residual part of Nanofat, the concentration of ADMSC and other cells was increased and transformed into a liquid that can be injected easily with $30 \mathrm{G}$ needle tip. In a study, Gentile., et al. conducted a Nanofat application to skin lesions due to burn or trauma and evaluated histologically the skin structure in the area treated with the biopsies in the $6^{\text {th }}$ month. They stated that the skin thickness and quality increased, new collagen and elastin structuring were observed and new blood vessels were observed in the previously traumatized tissue [26]. The improvement in vaginal epithelial mucosa and elasticity from VHI pa- 
rameters in the present study can be histologically explained with the collagen-elastin remodeling seen after Nanofat injection in the study of Genitlle., et al.

There are studies in the literature on the application of Nanofat to the genital area for regenerative purposes. For example, Tamburino., et al. stated that they achieved a satisfactory treatment success in treatment of Vulvar Lichen Sclerosis by using Nanofat due to regenerative capacities of ADMSCs [27]. In their study, Casabona., et al. also found that ADMSCs helped healing in Vulvar Lichen Sclerosis lesions [28]. Menkes., et al. applied nanofat to vagina and microfat to labia majora and evaluated the decreased genitourinary syndrome complaints of women in the peri-menopausal and post-menopausal age groups with VHI and FSFI scores. The follow-up continued until the $18^{\text {th }}$ month after treatment and statistically significant improvements were determined in VHI and FSFI scores [29]. In the present study, we found a statistically significant improvement in VHI and FSFI scores due to the regenerative effect of ADMSC after B SHOT injection in a group show no menopausal symptoms, expressing low sexual comfort and low daily vaginal health comfort, and having a younger age average. The results of the present study are compatible with the results of the study by Menkes., et al.

For genital area rejuvenation, other than Nanofat, SVF and ADMSC injection, hyaluronic acid fillers, collagen fillers, silicone fillers and fillings containing calcium hydroxyapatite are actively used [30]. Although it is not very frequently seen in the literature, adverse effects have been reported since these rejuvenation substances, which are foreign to the body, have a larger molecular structure compared to SVF and ADMSC. Hyaluronic acid is a safe and frequently used product in cosmetic gynecology. However, the patient who developed non- thrombotic pulmonary embolism after injection of $5 \mathrm{ml}$ hyaluronic acid made on the vaginal wall for rejuvenation was connected to the mechanical ventilator and was followed up in the intensive care unit [31]. In addition, fatal pulmonary embolism case was reported after injection of polyacrylamide hydrogel into the vaginal wall in the literature [32]. The fact that the final product (FAT JUICE) rich in ADMSC, that we used for rejuvenation purpose, is an autologous non-allergic product, in a liquid form that can be injected with $30 \mathrm{G}$ needle tip and smaller than 400 micron molecularly suggests that our technique is safer than other genital rejuvenation applications.

\section{Conclusion}

Our B-SHOT technique can be an alternative application to the genital rejuvenation protocols since the regenerative effects of adipose derived mesenchymal stem cells in stromal vascular fraction are benefited for genital rejuvenation, it is a practical application that can be applied in a short time without the need for additional staff or laboratory during the preparation phase, it is cost-effective and safe, and it positively affects FSFI and VHI parameters statistically. Longer term follow-up results and randomized controlled trials are needed.

\section{Conflict of Interest}

The authors declared no potential conflicts of interest.

Funding

None.

\section{Bibliography}

1. Rigotti G., et al. "Adipose-Derived Mesenchymal Stem Cells: Past, Present, and Future". Aesthetic Plastic Surgery 33 (2009): 271-273.

2. Clauser L., et al. "Autologous Fat Transfer for Facial Augmentation and Regeneration". Atlas of the Oral and Maxillofacial Surgery Clinics of North America 26 (2018): 25-32.

3. Zuk PA., et al. "Human Adipose Tissue Is a Source of Multipotent Stem Cells". Molecular Biology of the Cell 13 (2002): 4279-4295.

4. Hass R., et al. "Different populations and sources of human mesenchymal stem cells (MSC): A comparison of adult and neonatal tissue-derived MSC". Cell Communication and Signaling 9 (2011): 12 .

5. Rodbell M. "Metabolism of isolated fat cells". Journal of Biological Chemistry 239 (1964): 375-380.

6. Mizuno H., et al. "Concise Review: Adipose-Derived Stem Cells as a Novel Tool for Future Regenerative Medicine". Stem Cells 30 (2012): 804-810.

7. Horwitz EM., et al. "Transplantability and therapeutic effects of bone marrow-derived mesenchymal cells in children with osteogenesis imperfecta". Nature Medicine 5 (1999): 309-313. 
8. Schäffler A and Büchler C. "Concise Review: Adipose TissueDerived Stromal Cells-Basic and Clinical Implications for Novel Cell-Based Therapies". Stem Cells 25 (2007): 818-827.

9. Kasir R., et al. "Regenerative Engineering of Cartilage Using Adipose-Derived Stem Cells". Regenerative Engineering and Translational Medicine 1 (2015): 42-49.

10. Shah FS., et al. "A non-enzymatic method for isolating human adipose tissue-derived stromal stem cells". Cytotherapy 15 (2013): 979-985.

11. Tonnard P., et al. "Nanofat Grafting". Plastic and Reconstructive Surgery 132 (2013): 1017-1026.

12. Bachmann G. "Urogenital ageing: an old problem newly recognized”. Maturitas 22 (1995): S1-S5.

13. Sand M., et al. "The female sexual function index (FSFI): a potential "gold standard" measure for assessing therapeuticallyinduced change in female sexual function". Fertility and Sterility 92 (2009): S129.

14. Wiegel M., et al. "The Female Sexual Function Index (FSFI): Cross-Validation and Development of Clinical Cutoff Scores". Journal of Sex and Marital Therapy 31 (2005): 1-20.

15. Bora P and Majumdar AS. "Adipose tissue-derived stromal vascular fraction in regenerative medicine: a brief review on biology and translation". Stem Cell Research and Therapy 8 (20179): 145.

16. Aronowitz JA., et al. "Mechanical versus enzymatic isolation of stromal vascular fraction cells from adipose tissue". Springer Plus 4 (2015): 713.

17. Senesi L., et al. "Mechanical and Enzymatic Procedures to Isolate the Stromal Vascular Fraction From Adipose Tissue: Preliminary Results". Frontiers in Cell and Developmental Biology 7 (2019): 88.

18. Condé-Green A., et al. "Shift toward Mechanical Isolation of Adipose-derived Stromal Vascular Fraction". Plastic and Reconstructive Surgery 4 (2016): e1017.

19. Lin K., et al. "Characterization of adipose tissue-derived cells isolated with the Celution ${ }^{\mathrm{TM}}$ system". Cytotherapy 10 (2008): 417-426.
20. Amirkhani MA., et al. "Rejuvenation of facial skin and improvement in the dermal architecture by transplantation of autologous stromal vascular fraction: a clinical study". Bioimpacts 6 (2016): 149-154.

21. Cardoso AL., et al. "Adipose tissue stromal vascular fraction in the treatment of full thickness burns in rats". Acta Cirúrgica Brasileira 31 (2016): 578-585.

22. Rigotti G., et al. "Expanded Stem Cells, Stromal-Vascular Fraction, and Platelet-Rich Plasma Enriched Fat: Comparing Results of Different Facial Rejuvenation Approaches in a Clinical Trial". Aesthetic Surgery Journal 36 (2016): 261-270.

23. Klar AS., et al. "Characterization of vasculogenic potential of human adipose-derived endothelial cells in a three-dimensional vascularized skin substitute". Pediatric Surgery International 32 (2015): 17-27.

24. Aggarwal S. "Human mesenchymal stem cells modulate allogeneic immune cell responses”. Blood 105 (2005): 1815-1822.

25. Cheng C., et al. "Cell-Assisted Skin Grafting". Plastic and Reconstructive Surgery 137 (2016): 58-66.

26. Gentile P., et al. "Comparing different nanofat procedures on scars: role of the stromal vascular fraction and its clinical implications". Regenerative Medicine 12 (2017): 939-9952.

27. Tamburino S., et al. "The Role of Nanofat Grafting in Vulvar Lichen Sclerosus: A Preliminary Report”. Archives of Plastic Surgery 43 (2016): 93-95.

28. Casabona F., et al. "New Surgical Approach to Lichen Sclerosus of the Vulva: The Role of Adipose-Derived Mesenchymal Cells and Platelet-Rich Plasma in Tissue Regeneration". Plastic and Reconstructive Surgery 126 (2010): 210-211.

29. Menkes S., et al. "Microfat and Nanofat Grafting in Genital Rejuvenation". Aesthetic Surgery Journal (2020).

30. Vanaman M., et al. "Emerging Trends in Nonsurgical Female Genital Rejuvenation”. Dermatology Surgery 42 (2016): 10191029.

31. Park HJ., et al. "Hyaluronic acid pulmonary embolism: a critical consequence of an illegal cosmetic vaginal procedure". Thorax 65 (2010): 360-361.

Citation: Bülent Cihantimur., et al. "B-SHOT a New Technique in Genital Area Rejuvenation; Co-Injection of Stromal Vascular Fraction and Adipose-Derived Mesenchymal Stem Cell". Acta Scientific Medical Sciences 5.6 (2021): 158-166. 
32. Duan Y., et al. "Polyacrylamide hydrogel pulmonary embolism-A fatal consequence of an illegal cosmetic vaginal tightening procedure: A case report". Forensic Science International 238 (2014): 6-10.

Volume 5 Issue 6 June 2021

(c) All rights are reserved by Bülent Cihantimur., et al. 